\title{
DESCRIÇÃO DE DUAS ESPÉCIES NOVAS DE Neoplasta (COQUILLETT) (DIPTERA, EMPIDIDAE, HEMERODROMIINAE) DO PICO DA NEBLINA, AMAZONAS, BRASIL
}

\author{
José Albertino RAFAEL ${ }^{1,2}$
}

RESUMO - Duas espécies de Neoplasta Coquillett são descritas do Pico da Neblina, Brasil: N. neblina, sp.nov, e $N$. fregapanii, sp.nov.

Palavras-chave: Amazônia, Diptera, Empididae, Hemerodromiinae, Neoplasta

Description of Two New Species of Neoplasta Coquillett (Diptera, Empididae, Hemerodromiinae) from Pico da Neblina, Amazonas, Brazil.

ABSTRACT - Two new species of Neoplasta Coquillett are described from Pico da Neblina, Brazil: N. neblina, sp. nov, and N. fregapanii, sp. nov.

Key-words: Amazon Basin, Diptera, Empididae, Hemerodromiinae, Neoplasta

\section{INTRODUÇÃO}

Os adultos de Neoplasta Coquillett diferenciam-se dos demais hemerodromiíneos por apresentarem as pernas raptoriais anteriores pouco diferenciadas para apreensão das presas. O fêmur anterior é delgado, pouco mais volumoso que os posteriores, contrastando com outros gêneros da subfamília que apresentam o fêmur anterior notavelmente intumescido. Fêmur anterior pouco mais comprido do que a tíbia anterior, esta não possui cerdas espiniformes ao longo da face ventral nem a cerda apical, ventral, mais forte, caracteristica de outros gêneros. Todos tarsômeros 1 mais compridos que os demais. Veias $M_{1}$ e $M_{2}$ com pontos de origem separados (sésseis). Machos com tergito 8 reduzido, estreito, separado do esternito 8 , este bastante desenvolvido; machos e fềmeas com segmentos abdominais pré-genitais desesclerotinizados, geralmente retraídos pela desidratação.

Neoplasta ocorre no Novo Mundo com 12 espécies neárticas revisadas por MacDonald \& Turner (1993) e 21 espécies neotropicais catalogadas por Smith (1967). As espécies descritas abaixo são os primeiros registros para a Amazônia.

\section{MATERIAL E MÉTODOS}

O material foi coletado com armadilha Malaise montada sobre igarapé num platô a 2030 metros no maciço do Pico da Neblina.

A terminologia segue McAlpine (1981), exceto para a terminália masculina que segue Sinclair et al. (1994) e Cumming et al. (1995) e para a terminália feminina que segue Sinclair (1994).

As terminálias foram maceradas

\footnotetext{
Instituto Nacional de Pesquisas da Amazônia-INPA, Coordenação de Pesquisas em Entomologia, Caixa Postal 478, 69011-970, Manaus, Amazonas, Brasil. Email:jarafael@inpa.gov.br ${ }^{2}$ Bolsista do CNPq.
} 
em ácido lático à quente e examinadas em lâmina escavada com glicerina (Cumming, 1992). Ilustrações foram feitas em microscópio estereoscópico Wild M8 e em microscópio composto Leica DM LS, ambos equipados com câmara clara. As escalas foram obtidas através da projeção da imagem de uma lâmina micrométrica através da câmara clara. As partes desprendidas foram acondicionados em tubinhos plásticos (microvials) com glicerina e alfinetados através da cortiça junto ao espécime.

Em "Material examinado" as informações entre colchetes [] completam dados das etiquetas. Dados de cada etiqueta estão contidos entre aspas (""). Dados entre etiquetas estão separados por barra (/).

Neoplasta neblina, sp. nov. (Figs. 1-9)

Descrição (macho): Comprimento do corpo: $2,3-2,7 \mathrm{~mm}$; da asa: $2,6-3,1 \mathrm{~mm}$. Cabeça. Olho com reflexo esverdeado, iridescente. Facetas anteriores maiores logo abaixo da antena. Fronte, face e pós-crânio pretos, brilhantes com pruinosidade cinza na fronte, face e metade inferior do pós-crânio numa faixa estreita atrás do olho. Fronte quase da largura do tubérculo ocelar com cerdas diminutas. Face com cerdas distintas quase contígua medianamente. Póscrânio com pruína cinza esparsa e cerdas claras. Antena curta, amarela; flagelo agudo com cerdas pequenas, distintas. Probóscide curta, amarela. Tórax preto, brilhante com esparsa pruinosidade cinza. Cerdas diminutas exceto por uma notopleural, uma pós- alar e o par escutelar levemente mais longas. Pernas brilhantes, amarelas, exceto fêmur posterior marrom-claro medianamente e tarsômeros distais marrons. Fêmur anterior levemente mais volumoso que os posteriores, com 3-4 cerdas ântero-ventrais e póstero-ventrais basais mais fortes e mais longas e série de cerdas espiniformes ventrais curtas destacando-se uma cerda mediana mais forte. Fêmur médio com série de cerdas ântero-ventrais e pósteroventrais mais longas na metade basal. Asa (Fig. 1) hialina. Halter amareloclaro.

Abdômen: Segmentos prégenitais marrons a pretos, desesclerotinizados e retraídos pela desidratação. Terminália (Figs. 2-4). Tergito 8 (Fig. 2) muito reduzido e separado medianamente. Esternito 8 bastante desenvolvido. Cerco grande de ápice arredondado. Hipândrio (Fig. 4) curto e largo, membranoso ventralmente, exceto no ápice. Epândrio pequeno. Surstilo

(Fig.

3) inconspicuo. Gonóstilos (Fig. 4) fundidos na base, separados distalmente, cada extremidade fundindo-se com a parede interna do hipândrio. Falo com pequena estrutura semicircular e serrilhada distalmente.

Fêmea: Comprimento do corpo: $2,6-3,0 \mathrm{~mm}$; da asa: $2,6-3,1 \mathrm{~mm}$. Idêntica ao macho. Terminália (Figs. 5-9). Tergito 7 (Fig. 5) parcialmente desesclerotinizado. Esternito 7 esclerotinizado. Tergito 8 (Fig. 6) alongado com pequena fenda distal. Cerco projetado sob o tergito 10 . Esternito 8 como na Fig. 7. Esternito 10 (Fig. 8) em forma de $\mathrm{V}$ invertido. 
Forquilha genital como na Fig. 9.

Material examinado: BRASIL, Amazonas, S[anta] Izabel [do] R[io] Negro, Pico da Neblina, 8-12.x.1990" / "2030 m, Arm[adilha] Malaise, J.A.Rafael \& J.Vidal". Holótipo macho (INPA), 7 parátipos machos (5 INPA, 2 MZSP), 4 parátipos fêmeas (3 INPA, 1 MZSP).

Etimologia: O nome especifico é um aposto referente à localidade de coleta, Pico da Neblina.

\section{Neoplasta fregapanii, sp.nov. (Figs. 10-17)}

Descrição (macho): Comprimento do corpo: $2,2-2,6 \mathrm{~mm}$; da asa: $2,6-3,0 \mathrm{~mm}$. Muito semelhante à espécie anterior, exceto: par de cerda escutelar ausente; fêmur anterior sem cerda mediana mais forte na série ventral de cerdas espiniformes; fêmur posterior com mancha marrom-clara inconspícua medianamente; tibia média com pequenas cerdas espiniformes ventrais na extremidade distal; abdômen amarelo a marromclaro. Asa (Fig. 10) hialina. Halter amarelo-claro. Abdômen. Segmentos pré-genitais amarelos a marromclaros, desesclerotinizados e retraídos pela desidratação. Terminália (Figs 1112). Tergito 8 (Fig. 11) estreito em forma de arco. Esternito 8 grande. Cerco (Fig. 11) grande com pequena dobra na parede interna mais esclerotinizada e cerdas espiniformes curtas na face interna. Hipândrio (Fig. 12) de ápice estreito com diminutas cerdas distalmente, membranoso ventral-mente, exceto no ápice. Epândrio pequeno, suboval. Surstilo distinto. Gonóstilos (Fig. 12) separados, curtos.
Falo mais largo distalmente.

Fêmea: Comprimento do corpo: $2,6-2,9 \mathrm{~mm}$; da asa: $2,6-3,0 \mathrm{~mm}$. Idêntica ao macho.

Terminália (Figs. 13-17). Tergito 7 (Fig. 13) parcialmente desesclerotinizado. Esternito 7 esclerotinizado. Tergito 8 (Fig. 14) alongado com pequena fenda distal. Cerco projetado sob o tergito 10 . Esternito 8 como na Fig. 15. Esternito 10 (Fig. 16) em forma de $\mathrm{V}$ invertido. Forquilha genital como na Fig. 17.

Material examinado: "BRASIL, Amazonas, S[anta] Izabel [do] R[io] Negro, Pico da Neblina, 8-12.x.1990" / "2030 $\mathrm{m}$, Arm[adilha] Malaise, J.A.Rafael \& J.Vidal". Holótipo macho (INPA), 4 parátipos machos (2 INPA, 2 MZSP), 3 parátipos fềmeas (2 INPA, 1 MZSP).

Etimologia: O nome especifico homenageia um dos lideres da excursão ao Pico da Neblina em 1990, Coronel Gélio Augusto Barbosa Fregapani,

\section{AGRADECIMENTOS}

À Força Aérea Brasileira e Exército Brasileiro pelo apoio no transporte e logístico durante a excursão ao Pico da Neblina e Morro dos 6 Lagos, no extremo norte do Brasil, realizada em 1990. Ao técnico João Ferreira Vidal pelo auxílio nas coletas de campo.

\section{Bibliografia citada}

Cumming, J.M. 1992. Lactic acid as an agent for macerating Diptera specimens. Fly times 8:7.

Cumming, J.M; B.J. Sinclair.; \& D.M. Wood 1995. Homology and phylogenetic implications of male genitalia in Diptera - 


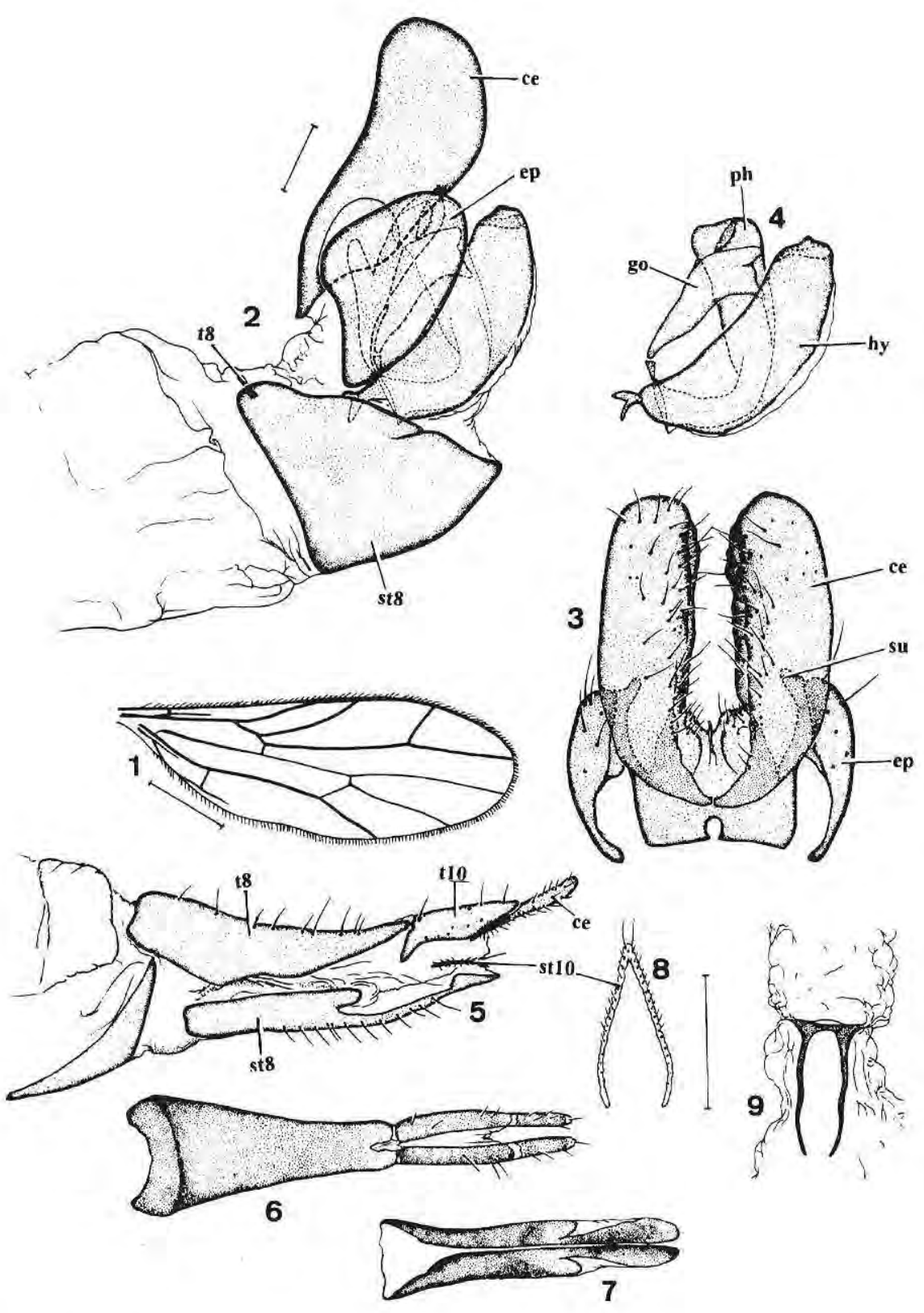

Figuras 1-9. Neoplasta neblina, sp. nov.: 1-4 parátipo macho, 5-9 parátipo fêmea. 1, asa; 2 , terminália, v. lat.; $\mathbf{3}$, terminália, v.d.; $\mathbf{4}$, hipândrio, falo e gonóstilo, v. lat.; $\mathbf{5}$, terminália, v. lat.; 6, tergito 8, tergito 10 e cerco, v. d.; 7, esternito 8, v. v;; 8, esternito 10, v.v.; 9, forquilha genital, v.v. Abreviaturas: $c e=$ cerco, $\mathrm{ep}=$ epândrio, $\mathrm{go}=$ gonóstilo, hy $=$ hipândrio, $\mathrm{ph}=$ falo, $\mathrm{st}=$ esternito, $\mathrm{su}=$ surstilo, $\mathrm{t}=$ tergito. Escalas: Fig. $1=0,5 \mathrm{~mm}$; figs. $2-7$ na mesma escala $=0,1 \mathrm{~mm}$; figs $8-9$ na mesma escala $=0,1 \mathrm{~mm}$. 


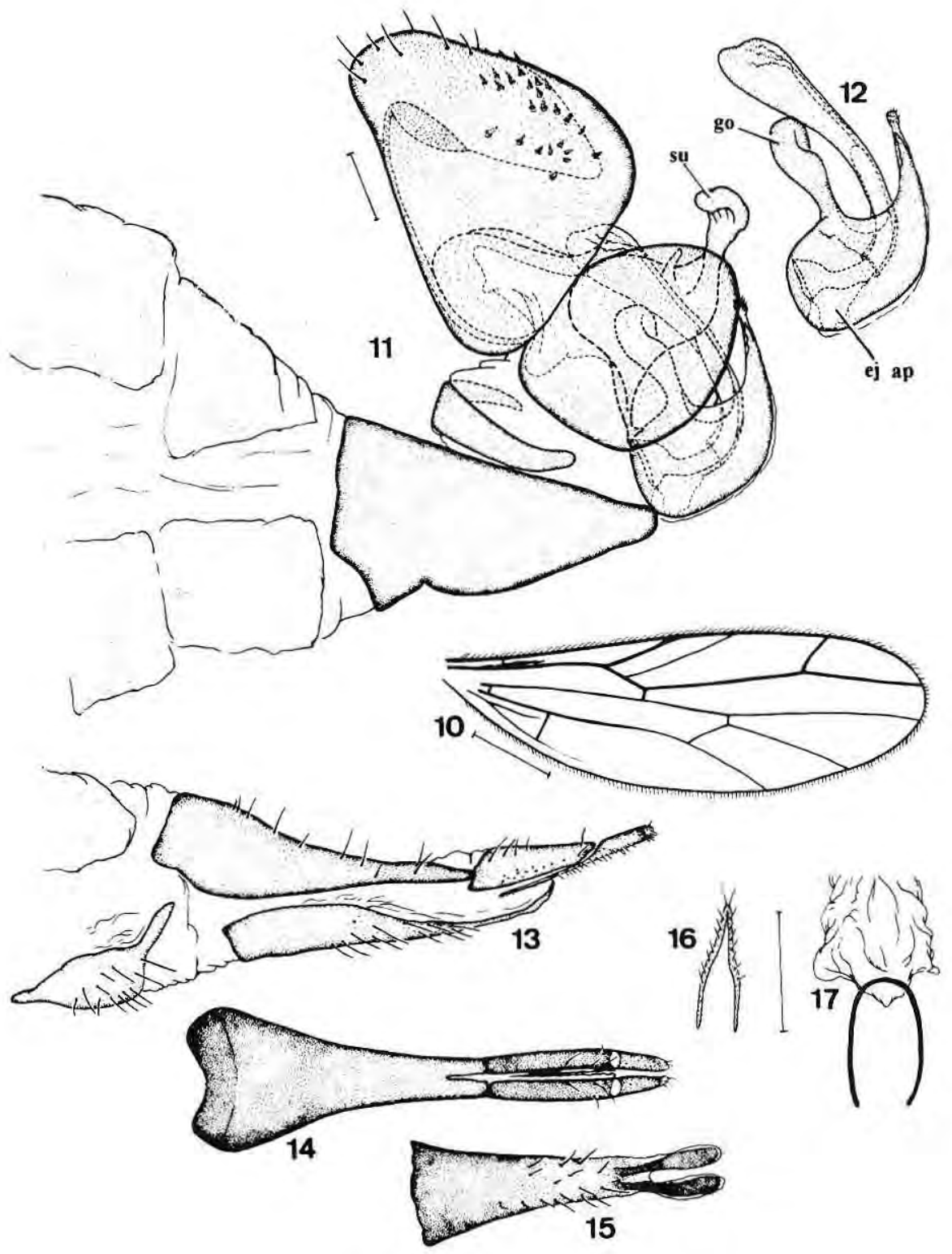

Figuras 10-17. Neoplasta fregapanii, sp. nov:: 10-12 parátipo macho, 13-17 parátipo fềmea. 10, asa; 11, terminália, v. lat.; 12, hipândrio, falo e gonóstilo, v. lat.; 13, terminália, v. lat.; 14, tergito 8 , tergito 10 e cerco, v. d.; 15 , esternito 8 , v. v.; 16, esternito 10 , v.v.; 17 , forquilha genital, v.v. Abreviaturas: ej ap $=$ apódema ejaculador, go $=$ gonóstilo, su $=$ surstilo. Escalas: Fig. $10=0,5 . \mathrm{mm}$; figs. $\mathbf{1 1 - 1 5}$ na mesma escala $=0,1 \mathrm{~mm}$; figs $\mathbf{1 6}-17$ na mesma escala $=0,1$ $\mathrm{mm}$. 
Eremoneura. Ent. scand. 26:120-151.

MacDonald, J.F. \& W.J. Turner 1993, Review of the genus Neoplasta Coquillett of America North of Mexico (Diptera; Empididae; Hemerodromiinae). Proc. Entomol. Soc. Wash. 95(3):351-376.

McAlpine, J.F. 1981. Morphology and terminology - adults, pp:9-63. In: Manual of Nearctic Diptera, vol. 1. McAlpine, J.F. et al. Eds. Monograph nr 27, Reserach Branch, Agriculture Canada.

Sinclair, B.J. 1994. Revision of Nearctic species of Trichoclinocera Collin (Diptera: Empididae; Clinocerinae). Can. Ent. 126:1007-1059.

Sinclair, B.J.; J.M.Cumming \& D.M. Wood 194. Homology and phylogenetic implications of male genitalia in Diptera - Lower Brachycera. Ent. scand. 24:407-432

Smith, K.G.V. 1967. Family Empididae. In: $A$ catalogue of the Diptera of the Americas South of the United States. Museu de Zoologia, Universidade de São Paulo, 39, pp:1-67. São Paulo, Brasil. 